\title{
An Assessment of a Public Health Initiative of Homeopathy for Primary Teething
}

\author{
Divya Taneja ${ }^{1}$ Anil Khurana ${ }^{1}$ Anil Vichitra ${ }^{1}$ Sarabjit Sarkar ${ }^{2}$ Arun Kumar Gupta ${ }^{3}$ Renu Mittal ${ }^{1}$ \\ Ramesh Bawaskar ${ }^{4}$ Amulya Ratan Sahoo ${ }^{5}$ Umakanta Prusty ${ }^{6}$ Shweta Singh ${ }^{1}$ Meera Sharma ${ }^{1}$ \\ Richa Pant ${ }^{4}$ Udaiveer Singh ${ }^{7} \quad$ Alok Kumar Upadhyay $^{8}$ Shruti Sehegal ${ }^{7}$ Satyashree Patnaik ${ }^{6}$ \\ Tapan Nath ${ }^{6}$ Raj K. Manchanda ${ }^{1}$
}

${ }^{1}$ Central Council for Research in Homoeopathy (CCRH), Delhi, India

2 Regional Research Institute (Homoeopathy), Guwahati, Assam, India

${ }^{3}$ Homoeopathic Drug Research Institute, CCRH, Lucknow, Uttar Pradesh, India

${ }^{4}$ Regional Research Institute (Homoeopathy), CCRH, Mumbai,

Maharashtra, India

${ }^{5}$ Drug Proving Research Institute (Homoeopathy), CCRH,

Bhubaneswar, Orissa, India

${ }^{6}$ Regional Research Institute (Homoeopathy), CCRH, Puri, Orissa, India

${ }^{7}$ Dr. D. P. Rastogi Central Research Institute (Homoeopathy), Noida, Uttar Pradesh, India

${ }^{8}$ Clinical Trial Unit for Homoeopathy, Gorakhpur, Uttar Pradesh, India
Address for correspondence Anil Khurana, MD(Hom), Central Council for Research in Homoeopathy, 61-65, Institutional Area, Opposite D Block, Janakpuri, Delhi - 110058, India (e-mail: anilnaman@rediffmail.com; anil23101961@gmail.com).

Homeopathy 2019;108:2-11.

\begin{abstract}
Keywords

- Accredited Social Health Activist

- Calcarea phosphoricum

- children

- dentition

- diarrhoea

- public health

- upper respiratory tract infections

Background During primary teething, children suffer from running nose, mild fever, diarrhoea and other mild irritations and inflammations. A public health programme, 'Homoeopathy for the Healthy Child', was undertaken on a pilot basis focusing on promotion of healthy teething by provision of home-based care through six preidentified homeopathic medicines for complaints commonly observed during primary teething. This article assesses the feasibility of this programme and reports the impact of this initiative on teething profile in children and episodes of diarrhoea and upper respiratory tract infection (URTI).

Materials and Methods Accredited Social Health Activists (ASHAs) were trained in child care and usage of a kit comprising six medicines, namely Calcarea phosphoricum 6X (CP), Ferrum phosphoricum 3X, Magnesium phosphoricum 6X, Belladonna 30C, Chamomilla 30C and Podophyllum 30C. Calcarea phosphoricum was given regularly to each participating child from 6 months to 1 year of age. Home-based care for diarrhoea, URTI and mild fever was provided by ASHAs using the other five medicines in the kit. Dentition pattern and diarrhoea/URTI episodes were recorded over a period of the next 12 months.

Results Eleven thousand four-hundred and twenty-six children were followed up regularly. Amongst those who enrolled at 6-7 months, a larger proportion of children were approaching expected teething in successive months as compared with children enrolled at 12 months, thus indicating that teething delays, if any, were overcome during this period. Incidence of diarrhoea and URTI showed decrease in the months after enrolment. Children responded favourably to the medicines given by ASHAs at the time of diarrhoea/URTI episodes, and ASHAs expressed satisfaction with the programme.
\end{abstract}

received

June 7, 2018

accepted after revision

August 30, 2018

published online

November 20, 2018
Copyright @ 2019 The Faculty of

Homeopathy
DOI https://doi.org/ 10.1055/s-0038-1673650. ISSN 1475-4916. 
Conclusion An approach with regular use of $\mathrm{CP}$ and home-based care with homeopathy through health workers for common problems in teething children is acceptable to the community and enhances outreach of services to the public at large. Observations in terms of the healthy teething period may be further validated through studies of homeopathy with suitable comparator group.

\section{Introduction}

The period associated with eruption of primary (deciduous) teeth in infants can be difficult and distressing for both child and parents, as this is often accompanied by minor signs/ symptoms such as increased salivation, drooling, running nose, mild fever $\left(<38.9^{\circ} \mathrm{C}\right)$, loss of appetite, diarrhoea, circum-oral rash, facial flushing, general irritability, sleep disturbance, crying, fussiness, ear rubbing on the side of the erupting tooth, intra-oral ulcers, inflammation of gingiva overlying the tooth, gum irritation and increased biting tendency. $^{1-3}$

There are studies which have identified no significant relation between teething, diarrhoea and fever. ${ }^{4-6}$ Many caregivers and parents attribute diarrhoea and fever to be associated with teething. ${ }^{7,8}$ However, diarrhoea and fever are common illnesses occurring in children, particularly in those under 5 years of age, and acute respiratory diseases and diarrhoea are leading causes of morbidity and mortality in young children globally-more so in low-income countries.

Diarrhoea is the third most common cause of death in under-five children, responsible for $13 \%$ deaths in this age group, killing an estimated 300,000 children in India each year. Young age, low socio-economic status, poor maternal literacy, presence of under-five siblings in the family, low birth weight, inadequate breastfeeding, malnutrition, and poor sanitation and hygiene practices of the mother are associated with a higher incidence of diarrhoeal diseases. Antibiotics are recommended in diarrhoeal diseases only for gross blood in stools or Shigella-positive culture, cholera, associated systemic infection or severe malnutrition. However, unwarranted anti-diarrhoeal drugs and injections are prescribed frequently in the community as reported in the National Family Health Survey-3, where 16\% and 30\% children were treated with antibiotics and 'unknown' drugs, respectively. ${ }^{9}$ Acute respiratory infections (ARIs) are another leading cause of death among under-five children in India. In developing countries, on an average, every child has five episodes of ARI per year, accounting for 30 to $50 \%$ of the total paediatric outpatient visits and 20 to $30 \%$ of the paediatric admissions. Community-based estimates report $70 \%$ of childhood morbidities in these children, due to ARI. Poor socio-economic factors, low levels of literacy, sub-optimal breastfeeding, malnutrition, unsatisfactory levels of immunization coverage and cooking fuel used (other than liquefied petroleum gas) are identified as risk factors for increasing burden of ARIs. ${ }^{10}$ As such, it is evident that there is concurrence of diarrhoea, low-grade fever and running nose in children, during the age of primary teething.
The early proponents of biochemistry or tissue remedies $^{11,12}$ mentioned Calcarea phosphoricum (CP) as one of the key elements of teeth and advocated $\mathrm{CP}$ for delays in teething $^{13,14}$ as also for promotion of healthy dentition. ${ }^{15}$ Use of CP has become prevalent over the years. It is included in almost all teething compounds available commercially and is known to be one of the most frequently prescribed medicines in children since its earliest homeopathic use ${ }^{16}$ to the present day. ${ }^{17}$ However, use of $\mathrm{CP}$ in children for promotion of healthy teething on a mass level has not been examined.

Homeopathic medicines are known to be useful for paediatric diarrhoea in studies conducted in India and other parts of the world. ${ }^{18-20}$ Studies have also identified usefulness of homeopathy for the treatment of ARIs. ${ }^{21-23}$ The anecdotal evidence and experience of practitioners suggest that homeopathy can be used for reducing morbidity during teething. ${ }^{24,25}$

The Central Council for Research in Homoeopathy (CCRH) is an autonomous body of the Ministry of AYUSH, Government of India, for organized research in homeopathy. Various research programmes are undertaken with the objectives of improving success rate of clinical practice. ${ }^{26} \mathrm{~A}$ pilot public health programme, 'Homoeopathy for the Healthy Child', was implemented by the CCRH, focusing on promotion of health care in children by giving regular $\mathrm{CP}$ from the age of 6 months to 1 year and by provision of home-based care. The programme documents using six pre-identified homeopathic medicines for complaints commonly observed during the primary teething period. This article assesses the feasibility of this programme and reports its impact in terms of teething profile in children and episodes of diarrhoea and upper respiratory tract infections (URTIs).

\section{Materials and Methods}

\section{Programme Coverage}

India is a large country of 29 states and 7 union territories. These are further divided into 593 districts. Each district is divided into sub-districts, which are known by different names (tehsil, taluka, community development block, police station, Mandal, revenue circle, etc.). ${ }^{27}$ This pilot programme was undertaken in 10 such community development blocks with limited access to medical facilities ( - Table 1 ). A homeopathic doctor was identified as the nodal officer in each block.

\section{Linkage with National Health Mission}

The Government of India launched a public health initiative, 'National Rural Health Mission' (NRHM), in 2005, with an objective to provide accessible, affordable and quality health 
4 Homeopathy for Primary Teething Taneja et al.

Table 1 Programme coverage areas

\begin{tabular}{|l|l|l|l|}
\hline No. & State & Districts & Blocks \\
\hline 1 & Delhi & New Delhi District & Delhi Cantonment \\
\hline 2 & Uttar Pradesh & Gautam Budh Nagar & Bisrakh, Dadri \\
\hline 3 & Uttar Pradesh & Gorakhpur & $\begin{array}{l}\text { Bhatahat, } \\
\text { Chargawan }\end{array}$ \\
\hline 4 & Odisha & Cuttack & Niali, Kantapada \\
\hline 5 & Assam & Kamrup & $\begin{array}{l}\text { Dhirenpara, } \\
\text { Central Zone }\end{array}$ \\
\hline 6 & Maharashtra & Palghar & Vikramgarh \\
\hline
\end{tabular}

care to the rural, under-served and vulnerable population. ${ }^{28}$ This mission was extended as the National Health Mission (NHM) in 2012. The Accredited Social Health Activist (ASHA) is a critical human resource of the NRHM and subsequently the NHM. The ASHA is a resident woman for every 1,000 population. She is trained and supported to function in her own village, securing people's access to health care services, enabling improved health care practices and behaviours and health care provision, as is essential and feasible at the community level. ${ }^{29}$ The ASHA functions in the community as a link worker or a facilitator, and as a community-level health care provider. $^{30}$ These ASHAs are trained in child health and nutrition, among other aspects such as women's reproductive health, newborn health and infectious diseases. This includes assessment of sick children, classification of fever, management of diarrhoeal diseases and ARIs, amongst others. $^{31}$ The ASHAs working in the selected blocks were inducted and trained to implement this programme.

\section{Development of Homeopathy Medicine Kit and Training Manual}

A medicine kit was developed with six medicines: namely, $\mathrm{CP}$ 6X, Ferrum phosphoricum (FP) 3X, Magnesium phosphoricum (MP) 6X, Belladonna (Bell) 30C, Chamomilla (Cham) 30C and Podophyllum (Podo) 30C. In previous studies, ${ }^{18-20}$ Cham and Podo were identified as the most frequently indicated medicines in paediatric diarrhoea, and Bell for fever with acute rhinitis $^{21}$; as such, these three medicines were included in the kit. Additionally, CP, MP and FP were included in the kit based on their traditional use in common problems of children.

Table 2 Indications for the use of medicines

\begin{tabular}{|l|l|l|}
\hline Medicine name & Condition & Dosage \\
\hline CP. 6X & All children in the age range 6-12 months & 1 tablet twice a day regularly until the age of 12 months \\
\hline FP. 3X & Child with anaemia & 2 tablets once a day for 1 month \\
\cline { 2 - 3 } & Child with fever & 2 tablets four times a day for maximum 3 days \\
\hline MP. 6X & Child with colic & 2 tablets dissolved in hot water for 1 to maximum 2 days \\
\hline Bell. 30C & Child with running nose, fever & $\begin{array}{l}3 \text { pills four times a day for maximum } 3 \text { days. } \\
\text { To be stopped earlier if the child gets better }\end{array}$ \\
\hline Cham. 30C & $\begin{array}{l}\text { Child with irritability, crankiness, restlessness, } \\
\text { no sleep, refusal to eat food, green stools }\end{array}$ & $\begin{array}{l}3 \text { pills four times a day for maximum } 3 \text { days. } \\
\text { To be stopped earlier if the child gets better }\end{array}$ \\
\hline Podo. 30C & Child with diarrhoea, yellow, offensive stool & $\begin{array}{l}3 \text { pills four times a day for maximum } 3 \text { days. } \\
\text { To be stopped earlier if the child gets better }\end{array}$ \\
\hline
\end{tabular}

A training manual for ASHAs was developed. This manual detailed dental structure, functions of teeth, common teethingrelated problems, information on home-based care of diarrhoea, early signs of dehydration, oral rehydration methods and usage details of the homeopathic kit. The manual was prepared in English and translated into local Indian languages: namely Hindi, Odiya, Assamese and Marathi for different blocks. ${ }^{32}$

Trainings for ASHAs were held at the time of induction and their skills were periodically reviewed in follow-up interactions. They were specifically trained to maintain date-wise records of dentition pattern, acute episodes of diarrhoea, fever, and respiratory infection, outcome of management and referral to a primary health centre (PHC)/subcentre (SC) as per individual needs.

\section{Intervention}

The ASHAs personally visit each household in their area from time to time, to identify women who require ante-natal care. After birth of the child, they continue periodical visits to assess the overall health of the child and escort the mother and child for immunization. Parents can approach the ASHA of their of activities of the ASHAs under the NHM, an additional component of provision of homeopathic medicines for dentition and for common ailments-that is, diarrhoea and cold/ URTI/fever and colic-was included (- Table 2). Calcarea phosphoricum 6X was given regularly to all children up to the age of 12 months. During an episode of diarrhoea, URTI or colic, a single medicine was selected from the kit by the ASHA, as appropriate to each child, and given for a period of 1 to 3 days, in addition to CP $6 \mathrm{X}$ being given regularly. Calcarea phosphoricum 6X was discontinued, however, beyond 12 months of age. Home management methods for general hygiene, management of diarrhoea by continuing oral rehydration and management of common cold or cough, as taught to the ASHAs under NHM, were continued. ${ }^{31}$

The ASHAs also, as a part of their routine care, visited the household frequently or were in contact with the parents by telephone or through a messenger to confirm health of the child. They were asked to maintain records of illness in the child and the medicine given in the register provided to them. They also recorded teething status of the child at the time of initiating $\mathrm{CP}$ and at each subsequent visit. They took region as and when their child is unwell. Within this framework 


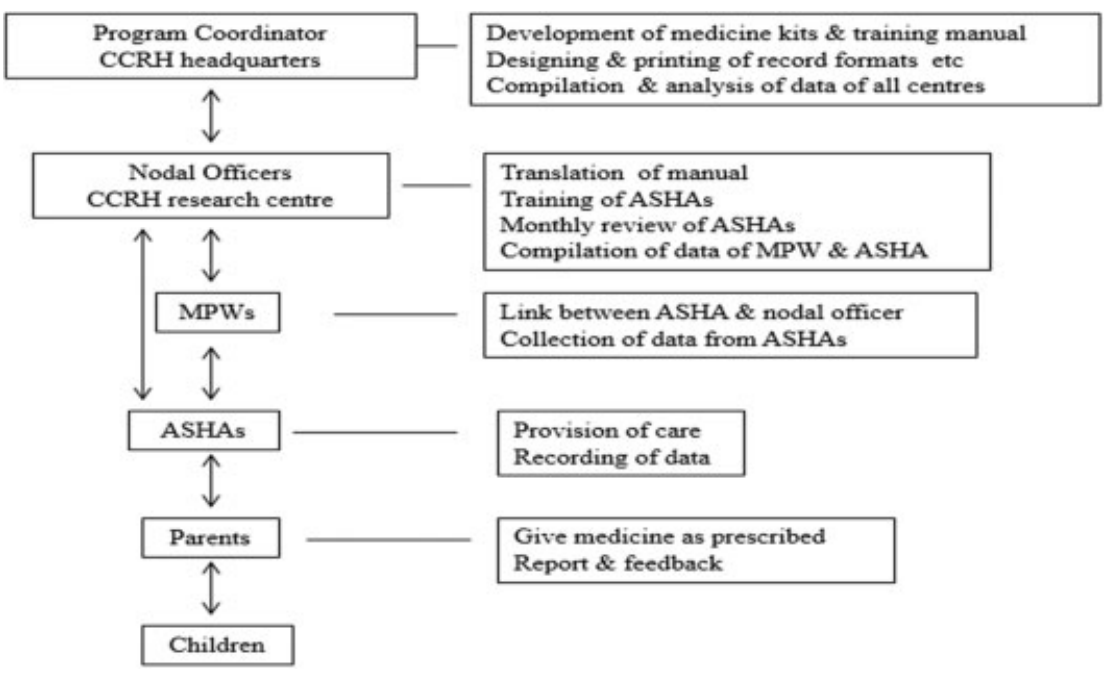

Fig. 1 Programme provision of care and flow of information. ASHAs, Accredited Social Health Activists; CCRH, Central Council for Research in Homoeopathy; MPWs, multi-purpose health workers.

verbal permission from parents to record these data and provide it to the nodal officers.

If the condition of any child deteriorated or there was no change in 3 days, the child was referred to the nearest health facility (PHC/SC for appropriate care). In no case was the medicine continued for more than 3 days.

\section{Review Meetings}

Review meetings were held monthly in the identified blocks by the nodal officer, assisted by other identified research associates/ fellows. Additionally, two multi-purpose health workers (MPWs) were posted in blocks with larger number of ASHAs, to interact with them on a regular basis. These MPWs move with the ASHAs in the field, identify their problems, compile data from them and report to the nodal officer daily. The details are given in - Fig. 1 .

\section{Assessment}

The nodal officers sent unlinked anonymized data to the coordinating centre, where data from all blocks were compiled.
An assessment of all children in the age group of 6 months to 12 months, completing 1-year follow-up, was made. Feedback from the ASHAs, seeking their perceived usefulness of the programme, was taken in a pre-designed questionnaire.

\section{Results}

In 25 group trainings, 1,064 ASHAs were trained, out of which 769 could work regularly and collect data. Eleven thousand four-hundred and twenty-six children ( $52.6 \%$ boys and $47.4 \%$ girls) were enrolled and followed up (-Table 3 ).

\section{Teething Pattern in Children}

Limited literature identifies expected numbers of primary teeth in each age group. Minor differences between boys and girls have also been reported. ${ }^{33}$ Age of primary teething was identified based on the number of teeth in children enrolled at different age groups (from 6 to 12 months). In each age group, the highest proportion of children with a specific

Table 3 Number of ASHAs and children enrolled and who were followed up regularly block-wise and age-wise

\begin{tabular}{|c|c|c|c|c|c|c|c|c|c|c|}
\hline S.no & Block & $\begin{array}{l}\text { No. of ASHAs } \\
\text { enrolling and } \\
\text { following children }\end{array}$ & $\begin{array}{l}6 \\
\text { months }\end{array}$ & $\begin{array}{l}7 \\
\text { months }\end{array}$ & $\begin{array}{l}8 \\
\text { months }\end{array}$ & $\begin{array}{l}9 \\
\text { months }\end{array}$ & $\begin{array}{l}10 \\
\text { months }\end{array}$ & $\begin{array}{l}11 \\
\text { months }\end{array}$ & $\begin{array}{l}12 \\
\text { months }\end{array}$ & $\begin{array}{l}\text { Total no. of children } \\
\text { followed up regularly }\end{array}$ \\
\hline 1 & Delhi Cantonment & 19 & 82 & 70 & 64 & 43 & 36 & 40 & 0 & 335 \\
\hline 2 & Vikramgad & 186 & 593 & 235 & 182 & 204 & 169 & 117 & 0 & 1500 \\
\hline 3 & Dadri & 75 & 107 & 89 & 34 & 203 & 130 & 108 & 323 & 994 \\
\hline 4 & Bisrakh & 73 & 359 & 366 & 381 & 340 & 426 & 247 & 841 & 2960 \\
\hline 5 & Central zone & 89 & 353 & 257 & 236 & 275 & 260 & 215 & 161 & 1757 \\
\hline 6 & Dhirenpara & 68 & 361 & 248 & 236 & 190 & 215 & 153 & 84 & 1487 \\
\hline 7 & Kantapada & 88 & 215 & 206 & 131 & 113 & 127 & 94 & 0 & 886 \\
\hline 8 & Niali & 151 & 262 & 235 & 230 & 184 & 203 & 174 & 1 & 1289 \\
\hline 9 & Chargawan & 16 & 23 & 8 & 18 & 12 & 32 & 15 & 28 & 136 \\
\hline \multirow[t]{2}{*}{10} & Bhatahat & 4 & 20 & 14 & 17 & 12 & 10 & 8 & 1 & 82 \\
\hline & Total & 769 & 2376 & 1728 & 1529 & 1576 & 1608 & 1171 & 1439 & 11426 \\
\hline
\end{tabular}

Abbreviation: ASHA, Accredited Social Health Activist. 
6 Homeopathy for Primary Teething Taneja et al.

Table 4 Age for primary teething

\begin{tabular}{|l|l|l|l|}
\hline $\begin{array}{l}\text { Number of } \\
\text { emerged } \\
\text { teeth }\end{array}$ & \multicolumn{2}{|l|}{$\begin{array}{l}\text { Age (in months) } \\
\text { for primary } \\
\text { teething as } \\
\text { identified in } \\
\text { literature }\end{array}$} & $\begin{array}{l}\text { Age (in months) for } \\
\text { primary teething as } \\
\text { identified for the } \\
\text { children under } \\
\text { this programme }\end{array}$ \\
\hline & Girls & Boys & All children \\
\hline 0 & & & 6 \\
\hline 1 & 7.72 & 7.55 & 7 \\
\hline 2 & 8.73 & 8.63 & 8.5 \\
\hline 3 & 9.76 & 9.60 & 10.5 \\
\hline 4 & 10.41 & 10.91 & 10.5 \\
\hline 5 & 11.15 & 10.76 & 11 \\
\hline 6 & 12.16 & 11.75 & 12.5 \\
\hline 7 & 13.13 & 13.01 & 13.5 \\
\hline 8 & 14.44 & 14.34 & 14.5 \\
\hline 9 & 15.72 & 15.26 & 16.5 \\
\hline 10 & 16.11 & 15.28 & 17.5 \\
\hline 11 & 16.35 & 16.20 & 17.5 \\
\hline 12 & 17.75 & 17.26 & 18.5 \\
\hline 13 & 19.25 & 18.47 & 19.5 \\
\hline 14 & 19.78 & 19.19 & 19 \\
\hline 15 & 20.45 & 19.74 & 20.5 \\
\hline 16 & 23.17 & 23.05 & 18.5 \\
\hline 17 & 25.77 & 26.48 & 18 \\
\hline 18 & 26.87 & 27.37 & 18.7 \\
\hline 19 & 28.19 & 28.28 & 20 \\
\hline & & & \\
\hline & & & \\
\hline & & &
\end{tabular}

number of teeth was identified, which was taken as the average teething age for that number of teeth ( - Table 4 ). Subsequently, age groups (beyond 12 months) were computed by identifying number of teeth in children being followed up over the period of 1 year.

Teething pattern in children, enrolled at age group of 6 to 12 months, was compared with the baseline teething status identified in the population. For this purpose, average age at which number of teeth emerged was taken as the baseline value and then compared with the number of children enrolled at various months. For example, from the average teething age data from our population, it was evident that children usually have one tooth at age of 7 months. Therefore, it was computed how many children enrolled at 6 months and 7 months, respectively, have one tooth at 7 months. The proportion of children highest among both the months was considered as reaching the average teething age. Hence, in this way the optimum age for starting $\mathrm{CP}$ to ease teething was computed.

A significantly larger number of children enrolled at 6 months as compared with those enrolled later had one tooth at 7 months, two teeth at 8 months, three teeth at 9 months, four teeth at 10 months, five teeth at 11 months and six teeth at 12 months (-Table 5). Only $3.9 \%$ of children enrolled at 12 months had six teeth, whereas $25.5 \%$ of children enrolled at 6 months had six teeth when they reached the age of
Table 5 Comparison among children enrolled at different months on number of teeth emerged

\begin{tabular}{|c|c|c|c|c|}
\hline $\begin{array}{l}\text { Number of } \\
\text { teeth at } \\
\text { the age } \\
\text { stated }\end{array}$ & $\begin{array}{l}\text { Proportion } \\
\text { of children }\end{array}$ & $\begin{array}{l}\text { Age at initial } \\
\text { enrolment } \\
\text { (months) }\end{array}$ & $\begin{array}{l}\text { Proportion } \\
\text { of children }\end{array}$ & $p$-Value \\
\hline $\begin{array}{l}1 \text { tooth at } \\
7 \text { months }\end{array}$ & 0.137 & 6 & 0.296 & $<0.001$ \\
\hline \multirow{2}{*}{$\begin{array}{l}2 \text { teeth at } \\
8 \text { months }\end{array}$} & \multirow[t]{2}{*}{0.246} & 6 & 0.365 & $<0.001$ \\
\hline & & 7 & 0.227 & 0.226 \\
\hline \multirow{3}{*}{$\begin{array}{l}3 \text { teeth at } \\
9 \text { months }\end{array}$} & \multirow[t]{3}{*}{0.180} & 6 & 0.241 & $<0.001$ \\
\hline & & 7 & 0.175 & 0.727 \\
\hline & & 8 & 0.135 & $<0.001$ \\
\hline \multirow{4}{*}{$\begin{array}{l}4 \text { teeth at } \\
10 \text { months }\end{array}$} & \multirow[t]{4}{*}{0.263} & 6 & 0.267 & 0.802 \\
\hline & & 7 & 0.228 & 0.027 \\
\hline & & 8 & 0.255 & 0.617 \\
\hline & & 9 & 0.145 & $<0.001$ \\
\hline \multirow{5}{*}{$\begin{array}{l}5 \text { teeth at } \\
11 \text { months }\end{array}$} & \multirow[t]{5}{*}{0.097} & 6 & 0.221 & $<0.001$ \\
\hline & & 7 & 0.211 & $<0.001$ \\
\hline & & 8 & 0.151 & $<0.001$ \\
\hline & & 9 & 0.128 & 0.013 \\
\hline & & 10 & 0.123 & 0.034 \\
\hline \multirow{6}{*}{$\begin{array}{l}6 \text { teeth at } \\
12 \text { months }\end{array}$} & \multirow[t]{6}{*}{0.039} & 6 & 0.255 & $<0.001$ \\
\hline & & 7 & 0.227 & $<0.001$ \\
\hline & & 8 & 0.241 & $<0.001$ \\
\hline & & 9 & 0.187 & $<0.001$ \\
\hline & & 10 & 0.205 & $<0.001$ \\
\hline & & 11 & 0.133 & $<0.001$ \\
\hline
\end{tabular}

12 months. Similarly, $22.7 \%$ of children enrolled at 7 months, $24.1 \%$ of children enrolled at 8 months, $18.7 \%$ children enrolled at 9 months, 20.5\% children enrolled at 10 months and 13.3\% children enrolled at 11 months; they had 6 teeth when they reached the age of 12 months. The figures indicate that a comparatively larger proportion of children enrolled in preceding months had the expected number of teeth for that age, implying that most of the children had near normal progress of teething. The children approaching the expected teething in the successive months indicated that teething lags (delays), if any, were overcome during this period. In 150 (52.44\%) children out of 286 children at 11 months with no teeth and 334 (84.55\%) out of 395 children at 12 months with no teeth, the first tooth appeared within 1 month of initiating CP.

\section{Incidence of Acute Illness Episodes}

Whereas teething pattern was identified to be more toward the expected number of primary teeth by specific age groups, frequency of diarrhoea and respiratory tract infections also reduced considerably during follow-up.

Diarrhoea incidence showed a decrease in subsequent months after enrolment in all age groups except 10 months and 12 months. In these children, although there was an increase in the immediate succeeding month, the incidence continued to fall over subsequent months (-Fig. 2). Additionally, children 


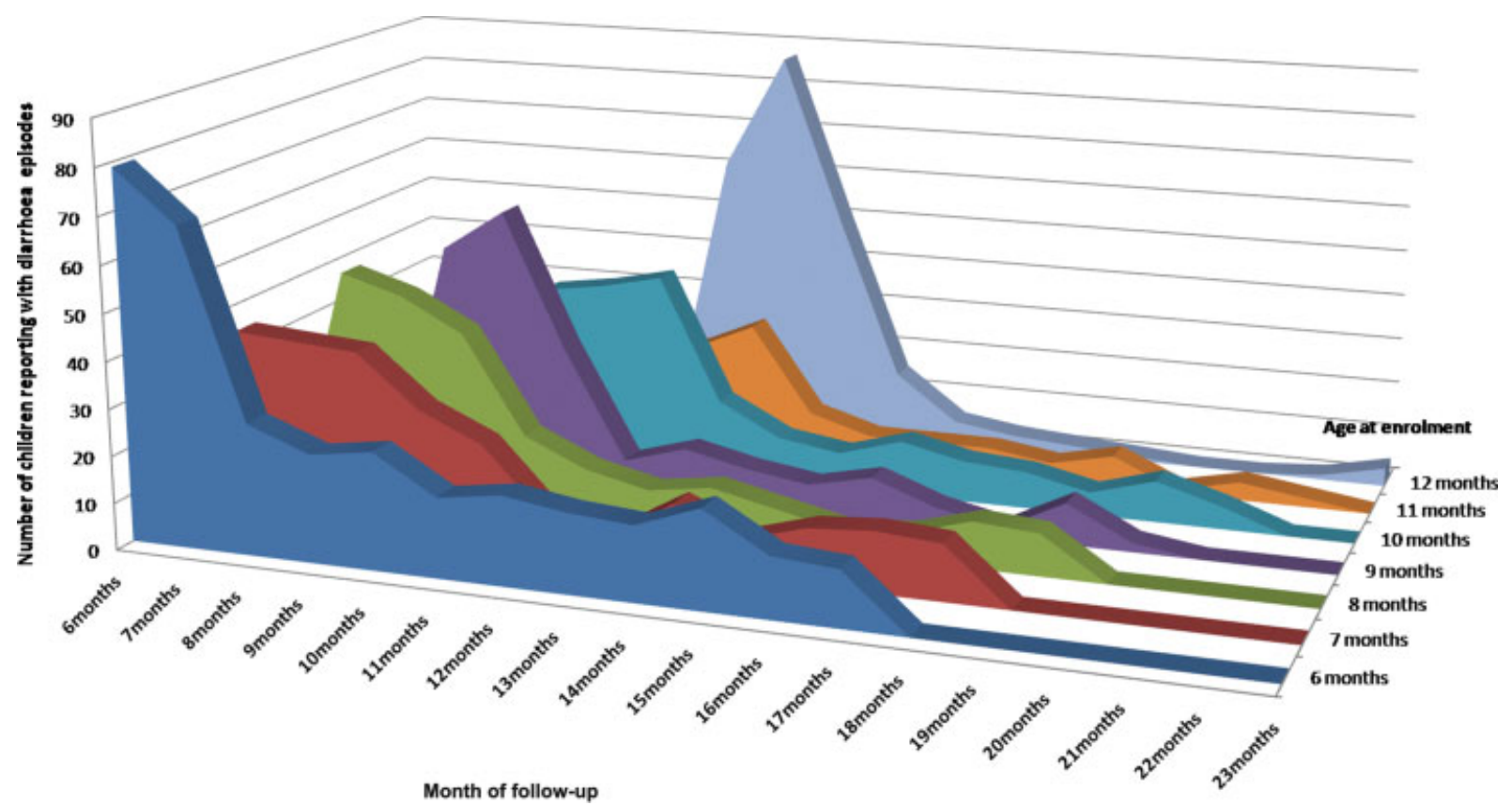

Fig. 2 Children reporting with diarrhoea episodes during follow-up.

responded to Cham (for greenish stool) or Podo (for yellowish stool) given at the time of a diarrhoea episode.

Running nose/URTI incidence showed a decrease in the subsequent months after enrolment in all age groups except 11 months, where a varying pattern of increase and decrease in episodes is seen (-Fig. $\mathbf{3}$ ).

\section{Usage of Kit}

Calcarea phosphoricum was used in 11,426 children until they reached the age of 1 year. Other medicines from the kit were used as and when required. Podo was used in 1,052 (9.20\%) episodes and Cham in 533 (4.66\%) episodes of diarrhoea. Bell was used in all 2,053 (17.96\%) cases with URTI. Additionally, MP was used in 207 (1.81\%) children with colic, FP in 244 (2.13\%) children with pallor suggestive of anaemia, and Cham in 233 (2.03\%) children with irritability (or crankiness). The ASHAs reported that the children responded to these medicines and only 10 children needed to be referred to SC/PHC.

\section{Referrals}

Only one case of a child with diarrhoea was referred at the age of 7 months, having been enrolled at the age of 6 months from the capital zone of Guwahati. Nine

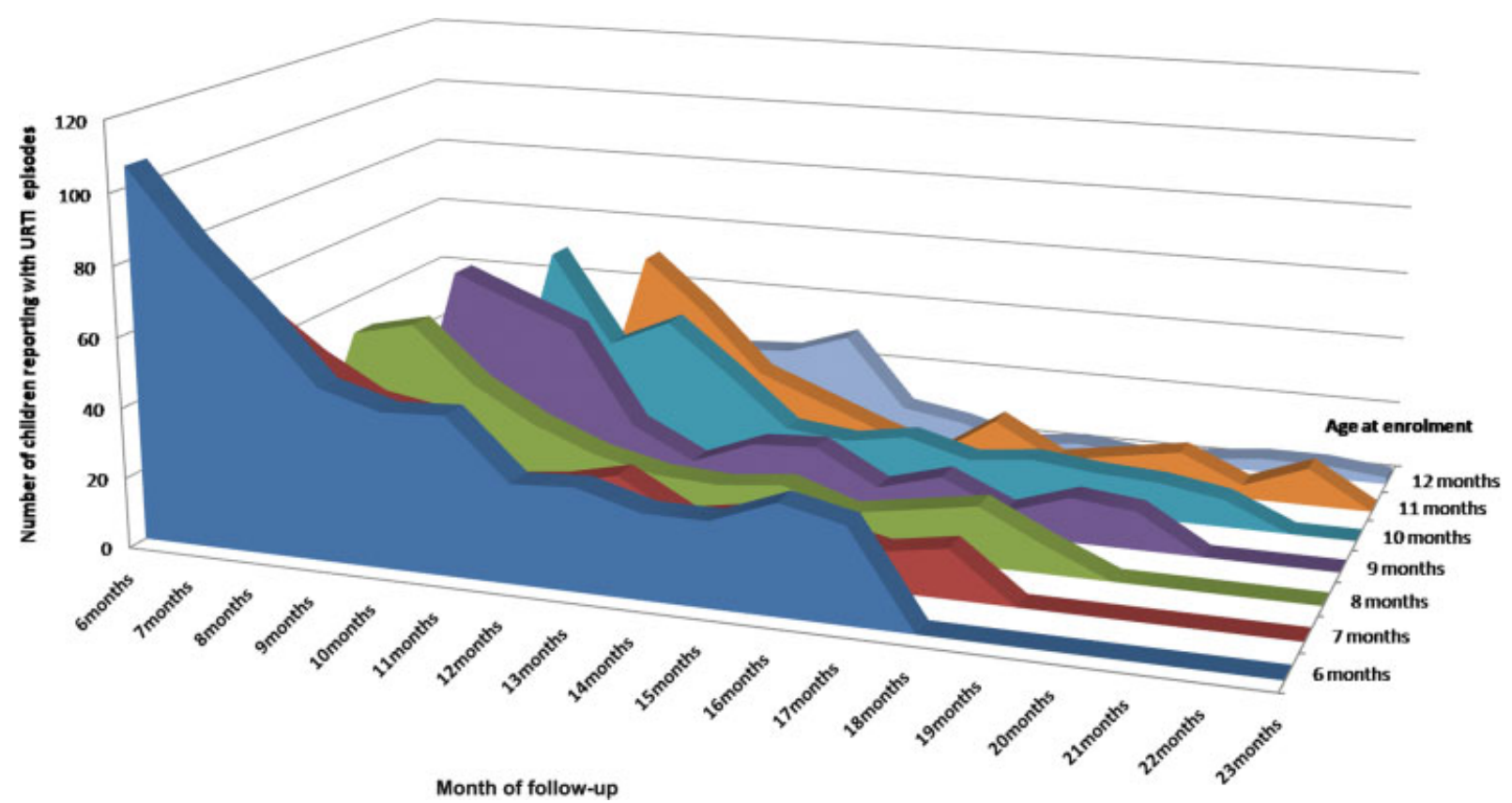

Fig. 3 Children reporting with running nose/URTI episodes during follow-up. URTI, upper respiratory tract infection. 
8 Homeopathy for Primary Teething Taneja et al.

Table 6 Cases presenting with diarrhoea/URTI/fever referred

\begin{tabular}{|l|l|l|l|}
\hline Block & $\begin{array}{l}\text { Age at } \\
\text { enrolment }\end{array}$ & Age at referral & Complaints \\
\hline Vikramgad & 7th month & 8th month & Fever \\
\hline Vikramgad & 10th month & 11th month & URTI \\
\hline Vikramgad & 8th month & 10th month & $\begin{array}{l}\text { URTI and } \\
\text { fever }\end{array}$ \\
\hline Vikramgad & 9th month & 11th month & URTI \\
\hline Vikramgad & 7th month & 10th month & URTI \\
\hline Vikramgad & 6th month & 14th month & Fever \\
\hline Niali & 10th month & 10th month & Fever \\
\hline Niali & 11th month & 14th month & URTI \\
\hline Kantapada & 9th month & 12th month & URTI \\
\hline Capital & 6th month & 7th month & Diarrhoea \\
\hline
\end{tabular}

Abbreviation: URTI, upper respiratory tract infection.

children with respiratory complaints were referred (-Table 6).

\section{Usefulness as Perceived by the ASHAs}

Five-hundred and eighty-one ASHAs who had provided care to children gave their feedback. Out of these, 566 responded that homeopathic medicines provided by them benefitted the children, 3 responded no effect and 12 did not respond to the question. In terms of effect on teething, 330 ASHAs responded that $\mathrm{CP}$ helped in easy teething, 41 ASHAs opined that it reduced complaints associated with teething and 195 responded $\mathrm{CP}$ eased teething as well as reduced associated complaints. The ASHAs identified the response to the medicines given for individual complaints and the number of days in which improvement was usually seen in children (-Tables 7 and 8). Out of 324 ASHAs who had provided treatment for diarrhoea, 316 were satisfied with the treatment response, whereas 3 were not satisfied and 5 did not respond to the question. Out of these ASHAs, 237 had concurrently provided oral rehydration salts as provided under NHM to the children. Out of 358 ASHAs who provided treatment for running nose/URTI, 349 were satisfied with the treatment, whereas 1 was not satisfied and 8 did not respond to the question.

Overall, 562 ASHAs expressed satisfaction with the programme being implemented, 6 were not satisfied and 6 responded that they were somewhat satisfied; 7 did not respond.
Table 8 Days to improvement identified by ASHAs

\begin{tabular}{|l|l|l|}
\hline Days & $\begin{array}{l}\text { Diarrhoea } \\
\text { (Experience of } \\
\text { 324 ASHAs) }\end{array}$ & $\begin{array}{l}\text { URTI / running nose } \\
\text { (Experience of } \\
\text { 358 ASHAs) }\end{array}$ \\
\hline Less than 1 day & 6 & 1 \\
\hline 1-2 days & 133 & 102 \\
\hline 3-4 days & 170 & 243 \\
\hline More than 4 days & 5 & 7 \\
\hline No improvement & 2 & 1 \\
\hline $\begin{array}{l}\text { No reply } \\
\text { from ASHAs }\end{array}$ & 8 & 4 \\
\hline
\end{tabular}

Abbreviations: ASHA, Accredited Social Health Activist; URTI, upper respiratory tract infection.

\section{Discussion}

Calcarea phosphoricum 6X was the only medicine given regularly to the children, from the time of their enrolment to the age of 12 months. The other homeopathic medicines were used only during acute illness episodes for 1 to 3 days, until the child either improved or was referred to the nearest health care facility. The results can, therefore, be associated more with the use of $\mathrm{CP}$ than with the other medicines being used only as short-term care. CP $6 \mathrm{X}$, found safe with no acute or long-term toxicity, ${ }^{34}$ has thus shown to have a promising role in primary teething in children.

A slight delay in teething, although not associated with morbidity, can be a cause of concern for the parents. Eruption timing for first primary tooth correlated with first permanent tooth eruption has also been reported. ${ }^{35}$ More than 20\% of the children enrolled at 6 months and 7 months in our study showed a near-normal teething pattern as compared with children enrolled at later months (-Table 5). Nearnormal teething pattern, as expected for that monthly age, was also seen in children enrolled later. CP $6 \mathrm{X}$ has addressed delayed teething in a favourable manner and seems associated with a healthy teething pattern. Additionally, progressive reduction in diarrhoea and URTI was seen after initiating regular CP 6X. It is suggested that although CP can be started at any age, it is best to start at 6 months, when the response is likely to be favourable, with a healthy teething pattern and a possible reduction in occurrence of diarrhoea and URTI. Although assessment of quality of teeth was neither an objective of the pilot study nor was expected

Table 7 Response identified by ASHAs providing home-based care for common complaints

\begin{tabular}{|l|l|l|l|l|l|}
\hline Teething associated complaints & Improve & No effect & Worsen & $\begin{array}{l}\text { Did not see } \\
\text { any cases }\end{array}$ & No reply from ASHAs \\
\hline $\begin{array}{l}\text { Symptoms of teething such as increased salivation, } \\
\text { irritability, and gum swelling }\end{array}$ & 515 & 11 & 0 & 4 & 51 \\
\hline Diarrhoea & 307 & 5 & 0 & 257 & 12 \\
\hline URTI/Cough & 348 & 1 & 0 & 223 & 9 \\
\hline
\end{tabular}

Abbreviations: ASHA, Accredited Social Health Activist; URTI, upper respiratory tract infection. 
from ASHA workers, the findings indicate undertaking a controlled study to quantify the effectiveness of $\mathrm{CP}$, with the assessment of quality of teeth as an additional parameter.

The evidence in favour of teething causing diarrhoea or other infections is conflicting. However, it has been repeatedly emphasised that there should not be any delay in diagnosis and in management of serious illnesses attributed to teething. ${ }^{36}$ Under this public health programme, ASHAs were able to provide immediate home-based care to children with diarrhoea and URTI, irrespective of whether the infections were attributed to teething or not. Treatment for diarrhoea and URTI with specific homeopathic medicines was largely acceptable and useful. The decreasing incidence of acute illness episodes can be attributed to better awareness, focused care and the timeliness of the medicine being given: the ASHAs and parents, maintaining due care of children consequent to their participation in the programme (Hawthorne effect), can also be responsible for decreasing episodes of acute illnesses in the enrolled children. Out of 11,426 children, only 10 referrals to $\mathrm{PHC} / \mathrm{SC}$ were required and there were no deaths. Considering that no adverse events occurred, utility of homeopathic medicine cannot be completely disregarded.

A limited amount of medicine, to be used only in specific conditions judiciously, in regular communication with the physicians, avoided any misuse. The ASHAs reported an increase in parents approaching them about children developing episodes of acute illness and were identified to be a useful channel for delivery of intervention at community level.

The findings favour the view that health workers can be trained to provide home-based care using some common homeopathic medicines, and which does not require knowledge of individualisation or symptom assessment as per the requirements of a classical homeopathic prescription. Only cases that do not respond to this first line of care need to be referred to the health facility, thereby reducing burden on these facilities in resource-constrained settings. The programme was thus found to be feasible and acceptable within the communities studied.

This was a public health programme for enhancing outreach, accessibility and availability of services through existing health care workers in the community, and was not inherently a clinical trial. The strength of the programme is that it utilises the existing health care infrastructure in the community and is dependent on health care workers for its success. The treatment strategy is integrated with the existing public health measures and is well accepted. It has a major limitation, however, with the absence of a control group. The government records that are available for diarrhoeal and respiratory episodes in children in a block PHC/SC do not consider children provided care by health workers and are therefore not comparable. The programme attempts to compile relative advantages of using homeopathic medicines as home-based care for specific conditions utilising community resources. Adequacy of the programme is thus affirmed, since the need to show causality of the intervention to the identified outcome warrants another study that uses a control group as a comparator. ${ }^{37}$ Meanwhile, the programme can be taken up in other regions where resource constraints delay provision of active health care services to children by trained physicians.

\section{Conclusion}

An approach with regular use of $\mathrm{CP}$ and home-based care with homeopathy through health workers for common problems in teething children is acceptable to the community and enhances outreach of services to the public at large. Considering the relative advantages identified, a controlled study on effectiveness of homeopathy in promoting healthy primary teething and its possible role in reducing incidence of diarrhoea and URTI in children is envisaged.

Highlights

- In a public health programme, Accredited Social Health Activists (ASHAs) were trained in child care and usage of a kit comprising six medicines, namely Calcarea phosphoricum 6X (CP), Ferrum phosphoricum 3X, Magnesium phosphoricum 6X, Belladonna 30C, Chamomilla 30C and Podophyllum 30C.

- Dentition pattern in 11,426 children who were given CP regularly in the age group of 6 months to 12 months was found approaching the expected teething in the successive months, indicating that teething lags (delays), if any, were overcome during this period.

- Children responded favourably to the medicines given by the health workers at the time of diarrhoea/upper respiratory tract infection (URTI) episodes, and diarrhoea and URTI incidence showed decrease in the months after enrolment.

- Such a programme based on provision of home-based care with a limited number of homeopathic medicines is feasible and acceptable to the community at large.

\section{Authors' Contributions}

RKM is the principal investigator who, along with AK, designed the programme and monitored it at all centres. He was responsible for manpower and resource management, including funding for the project, and ensured regulatory and administrative approvals. AK designed the resource material (ASHA manual, medicine kit) and study formats along with DT and coordinated the meetings and reviews at all centres. AV, SS, AKG, RM, RB, ARS and UKP were nodal officers of assigned blocks, who coordinated with local NHM officials, conducted ASHA trainings, reviews and compiled data from ASHAs within the block. ShwS, MS, RP, US, AKU, ShrS, SP and TN assisted nodal officers in their assigned blocks in review, feedback and data compilation from ASHAs. Data compilation from all centres was done by ShwS and MS. Data management and data analysis were done by DT and AK. RKM, DT and AK drafted the manuscript. All authors read and approved the final manuscript. 


\section{Funding}

The pilot programme is funded by the Central Council for Research in Homoeopathy, an autonomous body of the Ministry of AYUSH, Government of India.

\section{Conflict of Interest \\ None declared.}

\section{Acknowledgments}

We are thankful to the Ministry of Health \& Family Welfare and Ministry of Women and Child Development, Government of India for their support in implementation of the programme. We are also thankful to the National Health Mission officials in the blocks for their cooperation. Administrative support from those in charge of research institutes at Noida, Guwahati, Gorakhpur, Mumbai and Puri provided the required impetus. Programme implementation would not have been possible without the cooperation of health officers in the blocks.

We also acknowledge the support provided by the multi-purpose workers at Niali, Kantapada, Capital, Dhirenpada, Bisrakh, Dadri and Vikramgad blocks and data entry operators who, beyond their assigned duties, ensured smooth functioning of the project in the field. We are thankful to all the ASHAs and parents of the children for their participation.

Data analysis has been done by Dr. Rakesh Rana, Statistical Officer, and Ms Richa Singhal, Senior Statistical Assistant, Central Council for Research in Ayurvedic Sciences (CCRAS), New Delhi. The cooperation of Vaidya KS Dhiman, Director General, CCRAS, is acknowledged.

\section{References}

1 Sood M, Sood S. Problems with teething in children. Pediatr Oncall 2010;7:20 Available at: https://www.pediatriconcall.com/pediatricjournal/view/fulltext-articles/297/J/0/0/374/0 Accessed January 10, 2018 [serial online]

2 Memarpour M, Soltanimehr E, Eskandarian T. Signs and symptoms associated with primary tooth eruption: a clinical trial of nonpharmacological remedies. BMC Oral Health 2015;15:88

3 Ramos-Jorge J, Pordeus IA, Ramos-Jorge ML, Paiva SM. Prospective longitudinal study of signs and symptoms associated with primary tooth eruption. Pediatrics 2011;128:471-476

4 Editorial: Teething myths. BMJ 1975;4(5997):604

5 Gibbons HL, Hebdon CK. Teething as a cause of death. A historical review. West J Med 1991;155:658-659

6 Malkiel S, Eisenstadt M, Pollak U. Say a prayer for the safe cutting of a child's teeth: The folklore of teething. J Paediatr Child Health 2017;53:1145-1148

7 Wake M, Hesketh K, Allen M. Parent beliefs about infant teething: a survey of Australian parents. J Paediatr Child Health 1999; 35:446-449

8 Barlow BS, Kanellis MJ, Slayton RL. Tooth eruption symptoms: a survey of parents and health professionals. ASDC J Dent Child 2002;69:148-150, 123-124

9 Lakshminarayanan S, Jayalakshmy R. Diarrheal diseases among children in India: current scenario and future perspectives. J Nat Sci Biol Med 2015;6:24-28

10 Selvaraj K, Chinnakali P, Majumdar A, Krishnan IS. Acute respiratory infections among under-5 children in India: A situational analysis. J Nat Sci Biol Med 2014;5:15-20
11 Chapman JB, Schüssler WH. Biochemistry: A Domestic Treatise on the Application of Schussler's Twelve Tissue Remedies. St. Louis, MO: F. August Luyties; 1897

12 Boericke W, Dewey WA. The Twelve Tissue Remedies of Schüssler, Comprising the Theory, Therapeutic Application, Materia Medica, and a Complete Repertory of These Remedies. Homoeopathically and Bio-chemically Considered. Philadelphia, PA: Boericke \& Tafel; 1914

13 Boericke W. Care, Feeding and Homoeopathic Treatment of Children. San Francisco: Boericke \& Runyon Co.; 1911

14 Gibson DM. Calcarea phosphorica, A study. Br Hom J 1969; 58:185-188

15 Anshutz EP. Therapeutic By-Ways; Being a Collection of Therapeutic Measures Not to be found in the Text Books, Collected from all Sources. Philadelphia: Boericke \& Tafel; 1916

16 Sorrar WM. A digest of 10 years work at the Children's Sanatorium, Southport. J Br Homoeopath Soc 1898;6:82-94

17 Vithoulkas G. Calcarea Phosphorica. In Materia Medica Viva, Volume 6. International Academy of Classical Homeopathy; 1997

18 Jacobs J, Jonas WB, Jiménez-Pérez M, Crothers D. Homeopathy for childhood diarrhea: combined results and metaanalysis from three randomized, controlled clinical trials. Pediatr Infect Dis J 2003;22:229-234

19 Nayak C, Singh V, Singh K, et al. A prospective multicentric observational study to find the usefulness of the predetermined homeopathic medicines in the management of acute diarrhoeal disease in children. Am J Hom Med 2009;102:122-129

20 Patel M, Pawaskar N, Mundra P, Tamboli P, Kothare G. An approach to acute diarrhoeal disorders through sector and constitutional homeopathic treatment in tribal children attending Balwadis. Indian J Res Homoeopathy 2010;4:36-48

21 Nayak C, Singh V, Singh K, et al. A multi-centric open clinical trial to evaluate the usefulness of 13 predefined homeopathic medicines in the management of acute rhinitis in children. Int J High Dilution Res 2010;9:30-42

22 Nayak C, Singh VP, Singh H, et al. A prospective multicentric study to evolve the usefulness of group of homeopathic medicines in the management of acute tracheobronchitis. Int J Biol Res 2010; 2:9-14

23 Grimaldi-Bensouda L, Bégaud B, Rossignol M, et al. Management of upper respiratory tract infections by different medical practices, including homeopathy, and consumption of antibiotics in primary care: the EPI3 cohort study in France 2007-2008. PLoS One 2014;9:e89990

24 Jordan L. Could homeopathic medicine be utilised as a treatment for teething? Aust J Holist Nurs 2005;12:35-39

25 Central Council for Research in Homoeopathy Training Manual on Homoeopathy for Mother and Child Care, Vol. III. 2009

26 Ministry of AYUSH. Homoeopathy: Science of Gentle Healing. 2015

27 Office of the Registrar General \& Census Commissioner. Ministry of Home Affairs, Government of India. Available at: http://censusindia. gov.in/Census_And_You/Administrative_division.aspx. Accessed September 29, 2017

28 Ministry of Health and Family Welfare. National Rural Health Mission. Framework for Implementation 2005-2012. Ministry of Health and Family Welfare, Government of India. Available at: http://nhm. gov.in/images/pdf/about-nrhm/nrhm-framework-implementation/ nrhm-framework-latest.pdf. Accessed September 29, 2017

29 National Health Systems Resource Centre. ASHA. Which Way Forward...? Executive Summary - evaluation of ASHA programme. 2011. Available at: http://www.nipccd-earchive.wcd.nic.in/sites/default/ files/PDF/Evaluation_of_ASHA_Program_2010-11_Executive_Summary.pdf. Accessed September 29, 2017

30 Shashank KJ, Angadi MM. Assessment of roles and responsibilities of ASHA workers in Bijapurtaluk of Karnataka. Indian J Pharm Biol Res 2015;3:78-80 
31 National Rural Health Mission. ASHA Module 7. Skills that save lives. Available at: http://nhm.gov.in/images/pdf/communitisation/asha/ book-no-7.pdf. Accessed September 29, 2017

32 Central Council for Research in Homoeopathy. Training manual on health promotion during teething through Homoeopathy for ANM/ASHA \& AWW 2015

33 Hägg U, Taranger J. Dental development, dental age and tooth counts. Angle Orthod 1985;55:93-107

34 Singh S, Kalra P, Karwasra R, Khurana A, Manchanda RK, Gupta YK. Safety studies of homoeopathic drugs in acute, sub-acute and chronic toxicity in rats. Indian J Res Homoeopathy 2017;11:48-57
35 Poureslami H, Asl Aminabadi N, Sighari Deljavan A, et al. Does timing of eruption in first primary tooth correlate with that of first permanent tooth? A 9-years cohort study. J Dent Res Dent Clin Dent Prospect 2015;9:79-85

36 Kakatkar G, Nagarajappa R, Bhat N, Prasad V, Sharda A, Asawa K. Parental beliefs about children's teething in Udaipur, India: a preliminary study. Braz Oral Res 2012;26:151-157

37 Habicht JP, Victora CG, Vaughan JP. Evaluation designs for adequacy, plausibility and probability of public health programme performance and impact. Int J Epidemiol 1999; 28:10-18 